\title{
Research Notes
}

\author{
CONTENTS \\ Zheng Fan
}

483
Consulting Service at the Library of Tianjin University

ZHENG FAN

\section{Consulting Service at the Library of Tianjin University}

The Tianjin University is one of the oldest universities of China. Her predecessor was the National Peiyang University, founded in 1895. She was combined with the Hepei Institute of Technology in 1951, and the name was changed into Tianjin University. Soon the engineering colleges of Jingu University and Nankai University, as well as the Chemical Engineering Department of Yanjing University and others were merged into the Tianjin University in 1952 . There are thirteen departments and fourteen research institutes at present. The library of this university has a collection of more than one million volumes of books and more than 6,000 titles of periodicals.

The Library of Tianjin University consists of one office and four groups. These are: Acquisition and Cataloging Group; Circulating Group; Reference Group; and Literature Searching and Consulting Group (LSCG).

The LSCG was established in 1964, eliminated in 1966-1979 (a result of actions supporting the "gang of four"), and reestablished in May 1979. Its main responsibility is providing literature searching and consulting services.

Zheng Fan is head of Literature Searching and Consulting Group, Library of Tianjin University, the People's Republic of China.
There were 2,123 written inquiries from January 1962 to October 1980 . They may be divided into six categories (table 1).

\section{CATEGORIES OF INQUIRIES}

The purpose of a literature search is to understand the historical background, development, state of the art, and trends about a topic of research. In the United States, such a search is often done by computer, but it is done manually in our library. The search is often begun by researchers themselves. Occasionally, they ask for help from the library. We accepted 242 inquiries in this category.

\section{Identification from the Sources}

Chinese readers often have difficulties

TABLE 1

Categories of InQuiries

\begin{tabular}{|c|c|c|}
\hline tegory & Quantity & Percent \\
\hline $\begin{array}{l}\text { 1. Literature searching } \\
\text { 2. Identification from the } \\
\text { sources }\end{array}$ & $\begin{array}{r}242 \\
1,226\end{array}$ & $\begin{array}{l}11.36 \\
57.75\end{array}$ \\
\hline $\begin{array}{l}\text { 3. Reading problems } \\
\text { 4. Translation } \\
\text { 5. Calculating, design and }\end{array}$ & $\begin{array}{r}324 \\
20 \\
280\end{array}$ & $\begin{array}{r}15.27 \\
0.95 \\
13.20\end{array}$ \\
\hline $\begin{array}{l}\text { experimen } \\
\text { 6. Others } \\
\text { Total }\end{array}$ & $\begin{array}{r}31 \\
2,123\end{array}$ & $\begin{array}{r}1.47 \\
100.00 \\
\end{array}$ \\
\hline
\end{tabular}


identifying foreign literature sources, because they are unfamiliar with the foreign titles in abbreviation, acronyms, transliterations from Japanese or Russian characters, patent numbers and report codes, etc. There were 1,226 inquiries in this category, which was the largest category of our consulting services, over half (58 percent) of all inquiries. The 1,226 inquiries may be divided by types of literature as shown in table 2 .

\section{Problems in Reading}

There are many other questions that may arise when using research literature: personal names; place-names; institution names; trade names; abbreviations; acronyms; loan words; compound words; new technical terms; etc. This category involved 324 inquiries, being 15.27 percent of all consulting services.

\section{Translation}

After a preliminary review of the literature, readers may request translation of selected foreign articles into Chinese. This category involved only $20,0.95$ percent of all inquiries.

\section{Problems in Calculating, Design, and Experiment}

This category contained 280 inquiries, 13.20 percent of all inquiries. Most inquiries were to find the physical and chemical property of substances; data and behavior of materials; standards and product catalogs; types, parameters, and characteristic curves of electron tubes, transistors, or integrated circuits; etc.

\section{Others}

This category included inquiries that did TABLE 2

ThE TYPES OF 1,226 INQUIRIES

\begin{tabular}{lrr}
\hline \hline Type & Quantity & Percent \\
\hline Periodicals & 592 & 48.28 \\
Books & 207 & 16.89 \\
Patents & 133 & 10.85 \\
Reports & 100 & 8.16 \\
Standards & 72 & 5.88 \\
Conference papers & 71 & 5.79 \\
Theses and dissertations & 21 & 1.72 \\
Chinese materials & 20 & 1.63 \\
Product catalogs & 8 & 0.64 \\
Others & 2 & 0.16 \\
$\quad$ Total & 1,226 & 100.00 \\
\hline
\end{tabular}

not belong to the above five categories, but that also require consulting the literature, such as the departments and research programs of foreign universities, the specialties and works of some experts, etc. There were 31 inquiries in this category, being 1.47 percent of the whole consulting service.

Among the 2,123 consulting requests, 1,093 inquiries were from teachers, 330 from postgraduates, 579 from undergraduates, and 121 from readers outside the university.

\section{EFFECTS}

Through more than two thousand inquiries, we believe that the consulting service is one of the important links in the college and university library. It saves time for the researchers, and it speeds up the development of research.

\section{To Promote the Development of Scientific Research}

A scientific research group of our university engaged in research work for a new product of GTO (Gate turn off) thyristor. There were no positive results after three years of their experiments. Then this group asked us to provide some relevant literature on this subject. The information provided by us enlightened the research team. Referring to the literature, they made a series of changes in their experiments. Their new product won the first award from the Tianjin municipal government in February 1980.

\section{Full Utilization of the Collection of Our Library}

A teacher needed a document; its number was R-921-ARPA. The teacher could not interpret the code and asked us for help. We discovered that R-921-ARPA is a report from the Rand Corporation, prepared for the U.S. Advanced Research Projects Agency in November 1971. Its title was "Soviet Chemical Laser Research: Pulsed Lasers." However, our library did not have R-921-ARPA. After further research, we found that the report was also available as AD 740312.

Another teacher wanted to read a conference paper, ASME-ASLE Paper No.55-LUB22 . We found this paper was one of the papers of the Second Annual ASME-ASLE Lubrication Conference in 1955. Its title was "Analysis of Elliptical Bearings," by $\mathrm{O}$. 
Pinkus. Through several sources, we located this paper in the Transactions of ASME, Vol.78, No.5, p.965-73, 1956.

In both the cases above, through their inquiries, our teachers more fully utilized the collection of our library. They avoided time losses and expenses for trips to Peking, duplication, etc.

\section{Improvements in the Cataloging Work}

Sometimes some items could not be located through our catalog. The International Quantum Electronics Conferences used different titles for each proceeding; e.g., first proceedings were named as "Quantum Electronics - A Symposium," second named "Advances in Quantum Electronics," third, "Quantum Electronics: Proceedings of the Third International Congress," etc.

Sometimes the conferences were held in various countries and the proceedings were also written in various languages; such as the International Symposium on High Speed Photography, the second and tenth proceedings in French, fourth and seventh in German, and others in English. Inquiries about these helped us to improve our cataloging.

\section{To Supplement the Library Collection}

From the readers' inquiries, we came to understand what books were lacking in our library and we tried to acquire them. From an inquiry, we knew an eight-language volume on watches and clocks entitled the "Dictionnaire Horloger" published in Switzer- land in 1976 was not in our library. We ordered it for our collection.

\section{Dissemination of a Lecture Series on Literature Searching}

At the invitation of our instructors, we gave a lecture series on literature searching. Subjects included were: internal combustion engines; solar energy; radio electronics; and lasers. These lectures were especially effective when we used specific inquiries to illustrate how to search literature.

\section{To Change the Passive \\ Position into Initiative}

The consulting work is a passive service, but from the many inquiries received we became aware of the activities of our readers. We can now initiate some services, such as collecting and collating information, or compiling special bibliographies or indexes. Recently, a teacher requested information about geothermal energy. Soon another teacher repeated this inquiry. We learned that there was a conference on geothermal energy at Tianjin in 1971. So we compiled a special bibliography on geothermal energy. This bibliography was well received and has been heavily used by the teachers of our university who participated in the discussion by the Geothermal Group of Tianjin.

Through the consulting service our library has promoted the development of research, fully utilized its collections, improved the library's services, and has taken the initiative in some areas.

\section{REFERENCES}

1. Fan, Zheng, "Probing into the Consulting Work of a Library of Engineering University" (Presented at the First National Conference of Chinese Library Society, July 10, 1979, Taiyuan, Shanxi) (in Chinese).

2. Fan, Zheng, "Probing into the Scientific Literature Searching"

(Presented at the First National Conference of the Scientific and Technical Information Society of China, December 1979, Kunmin, Yunnan) (in Chinese).

3. Fan, Zheng, "Techniques and Procedures for Solving the Inquiries on Scientific and Technical Literature," Scientific and Technical Information Work, no.3:13-16 (1980) (in Chinese). 


\section{NOW ONLINE!}

\section{BOOKS IN PRINT}

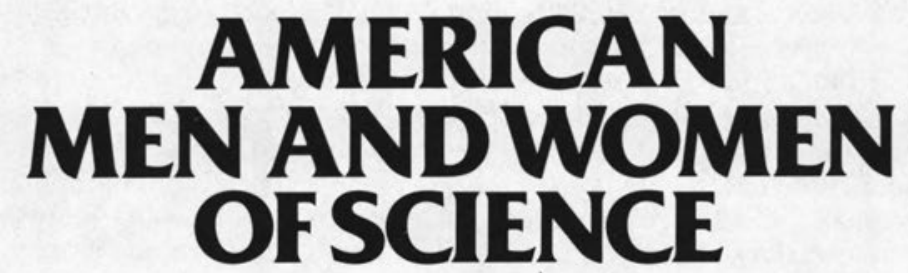

\section{ULRICH'S}

INTERNATIONAL

PERIODICALS DIRECTORY

\section{Maximize resources while saving time and money...}

Online access is now available initially through Bibliographic Retrieval Services (BRS) to the databases of three of the most frequently consulted Bowker reference books in your library. Employing these databases will provide currency, speed, and accuracy at each step of your reference, research, and acquisitions process. 


\section{BOOKS IN PRINT}

Updated monthly, the Books in Print database provides access to current data on over 660,000 bibliographic entries of which 60,000 are Forthcoming Books up to six months in advance of publication and 40,000 titles declared out of print by publishers since July 1979. All entries are classified under more than 80,000 Library of Congress subject headings, Sears headings for children's books and paperbound headings, where appropriate.

The BIP database can be searched by author, title, publisher, subject as well as any combination of these and other bibliographic elements. In a matter of seconds, you can perform complex searches which would take many hours to complete manually. Answers to queries for reference, research and acquisitions purposes will be at your fingertips.

\section{AMERICAN MEN AND WOMEN OF SCIENCE}

This most comprehensive directory of its kind provides full biographies of 130,500 U.S. and Canadian scientists active in 65 disciplines.

Online access to this database allows location of desired information more quickly than before and greatly facilitates more specialized and more exhaustive searches. In seconds you can locate scientists by university, degree year, scientific discipline, research interests, residence, honors and awards, as well as by other criteria.

\section{ULRICH'S INTERNATIONAL PERIODICALS DIRECTORY}

The Ulrich's database, which includes Irregular Serials and Annuals, is a unique and comprehensive source of information on periodicals and serials published throughout the world. It provides 102,000 complete bibliographic citations, covering 65,000 periodicals and 38,500 serials, annuals, continuations, and conference proceedings-all organized under 385 subject headings and updated monthly.

Contact, buying and ordering information, subject coverage, advertising data, and circulation figures for active entries are supplied to make profiling for subscriptions, advertising and P.R. list compilation quick and easy. Also included is a listing of more than 10,000 ceased titles from 1974 on.

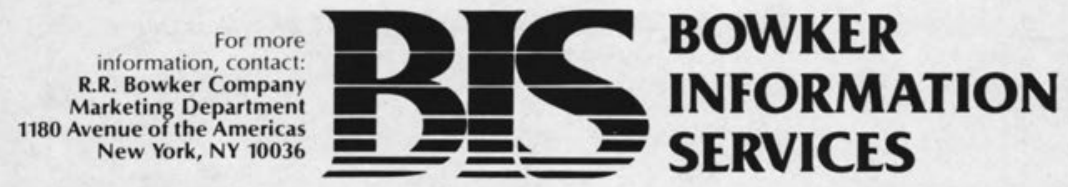




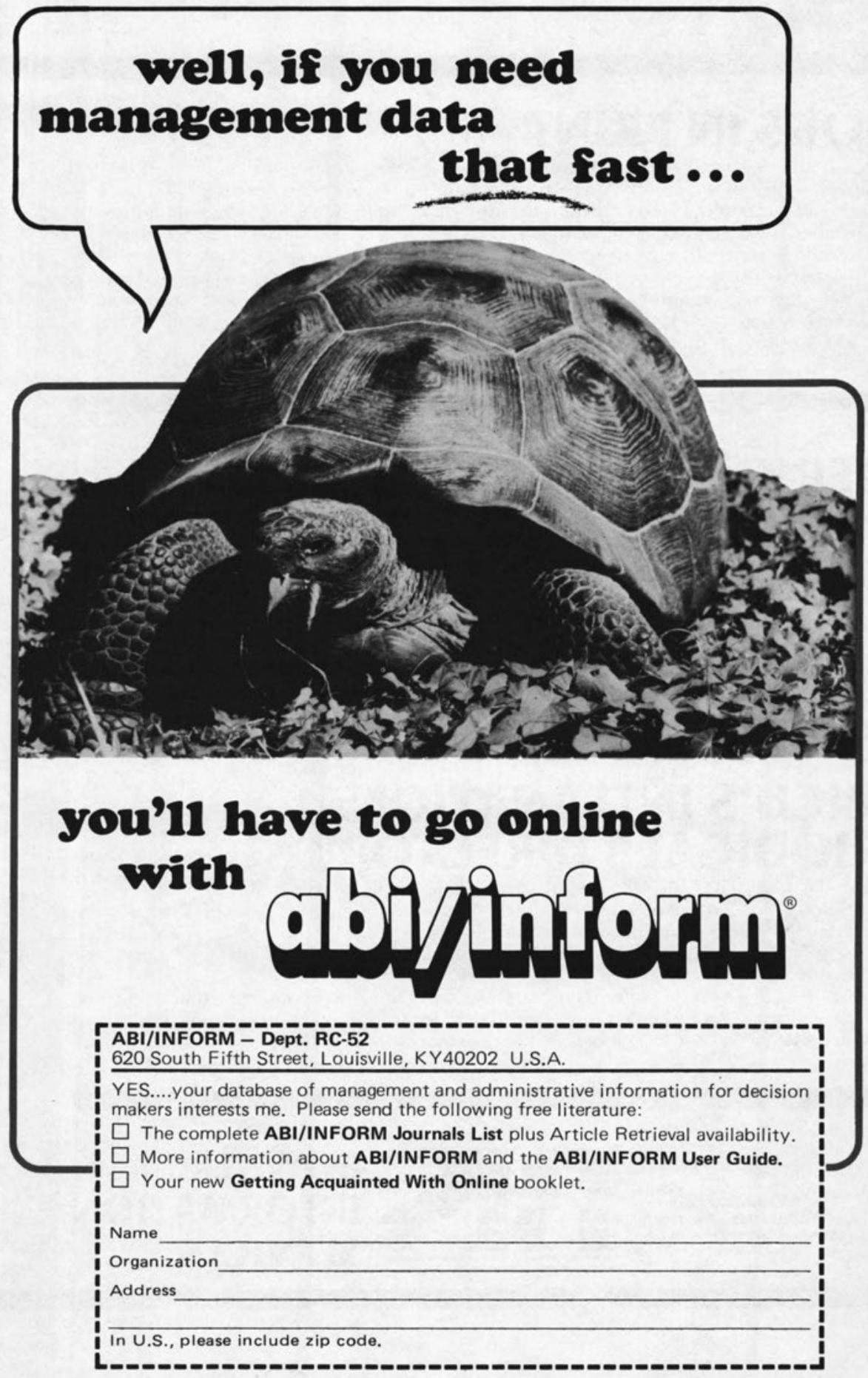

